\title{
Flipped Classroom Model for Teaching Undergraduate Students in Radiology
}

\author{
Shaista Afzal and Imrana Masroor \\ Department of Radiology, The Aga Khan University Hospital, Karachi, Pakistan
}

\begin{abstract}
Objective: To determine the effectiveness of teaching through flipped classroom model on learning and acceptability of undergraduate medical students in their radiology clerkship.

Study Design: Quasi-experimental design.

Place and Duration of Study: Radiology Department, The Aga Khan University Hospital, Karachi, from July to September 2018.

Methodology: Two groups (A and $B$ ) of third year medical students during their two weeks radiology clerkship were included. The topic of "chest X-ray" interpretation was presented in the flip classroom format to group B, while for the group A the same topic of chest X-ray was taught by traditional didactic lecture. The scores of the end of clerkship test of both groups were analysed using independent sample t-test. At the end of the clerkship, the students in group B completed the survey to share their experience and perception of flipped classroom model.

Results: A total of 40 third-year students participated in the study, 20 in each group. The mean test scores in the end of rotation test of group A was 7.3 and of group B was 7.2. No significant difference in the post-test scores was observed. Students' feedback on the experience of this pedagogical approach was positive and they also shared a few suggestions. Conclusion: Flipped classroom model had no significant impact on the end of clerkship test scores of medical students; however, an increased perceived value and acceptability of this model was noted by the participants.
\end{abstract}

Key Words: Flipped classroom, Clerkship, Perception, Learning experience, Pedagogy.

How to cite this article: Afzal S, Masroor I. Flipped classroom model for teaching undergraduate students in radiology. J Coll Physicians Surg Pak 2019; 29(11):1083-6.

\section{INTRODUCTION}

Medical education requires a mastery of extraordinary vast knowledge and attainment of technical skills and vocabulary in a short span of time. Hence, didactic teaching, e.g. traditional large group lectures have been predominantly employed to deliver this large volume of information. However, this entails minimum student/ teacher interaction and is thus not ideal for inculcating the problem-solving and knowledge-discovery skills, which are the requirements for medical practice. 1,2 This issue, in medical education, has been addressed by complementary instructional methods, that have succeeded in filling in the information gaps, promoting the application of knowledge, fostering critical thinking and preparing students to meet the challenges encountered in the context of patient care and clinical decision. 3,4

One form of this instructional design utilises the blended learning pedagogy. In recent years, a proliferation of blended learning, which involves a combination of online

Correspondence to: Dr. Shaista Afzal, Department of Radiology,

The Aga Khan University Hospital, Karachi, Pakistan

E-mail: shaista.afzal@aku.edu

Received: January 30, 2019; Revised: April 19, 2019;

Accepted: April 19, 2019 and face-to-face elements, has been reported. This teaching method has been documented to be more effective than either of the online or face-to-face alone and involves integration of the two with a clear vision for the improvement of student's learning. ${ }^{5}$ The flipped classroom model is a type of blended learning based on notion that technology can be used to change the oncampus teaching by inverting the classroom. This means that "events that have traditionally taken place inside the classroom now take place outside the classroom and vice versa". ${ }^{6}$ The principal goal of this model is to attain student-centred learning, to encourage collaboration with improvement of peer-to-peer interactions and to promote critical thinking. ${ }^{7}$

In this pedagogical approach, the students work independently outside the classroom to study basic concepts through different methods like online lectures, videos and articles etc. The learning is self-paced and the classroom time is then used for application of learnt material in the class. ${ }^{8}$ The students are engaged in activities that focus on development of skills that concern the application of concepts and factual knowledge they have acquired through earlier self-study. ${ }^{9}$ Hence, the educator's role shifts towards facilitation of deeper learning. ${ }^{10}$ This method, however, requires that the students come prepared for the class so that the discussions are more dynamic and interactive. 
The flipped classroom model has shown a prospective impact on medical education and studies have reported an improvement of students' performance and examination scores with this approach. ${ }^{11}$ At the study place, the undergraduate radiology core curriculum has been predominantly delivered through didactic teaching. This methodology of didactic teaching, however, may not be perfect for the development of problem-solving skills and knowledge acquisition that is essential for radiology and other medical specialties. 12 Therefore, other instructional approaches have been explored to competently overcome the knowledge gaps, enhance and promote knowledge application, critical thinking skills and prepare our medical students for the clinical decision-making faced during patient management.

The purpose of this study was to determine the effectiveness of teaching through flipped classroom model on learning and acceptability of undergraduate medical students in their radiology clerkship at The Aga Khan University Hospital.

\section{METHODOLOGY}

This quasi-experimental study was conducted from July to September 2018 in the Department of Radiology at The Aga Khan University Hospital, Karachi, after approval from the Department Elective and Undergraduate Committee (EUC) and institutional Ethics Review Committee (ERC). Two groups from third-year (A and $B$ ) were included during their two weeks radiology clerkship, each comprising of 20 students. The topic of "chest X-ray" interpretation was presented in the flip classroom format to group B; while for the group A, the same topic of chest $X$-ray was taught by traditional didactic lectures both covering the same learning objectives and curriculum. For the face-to-face component of the flipped classroom, clinical scenarios were designed for students engagement and application of factual knowledge.

Prior to the commencement of the study, the didactic lecture and the online resource for the flip class were peer reviewed for coverage of content and objectives by two different radiologists who had additional qualification in medical education. The students in the flipped classroom cohort were provided a flexible learning environment and they completed the online resource, i.e. the tutorial at their own place. This was followed by an interactive face-to-face session, in which they were presented with clinical scenarios and the relevant imaging. The students would interpret the images and reach a logical conclusion. The face-to-face session was adapted by the instructor to cover challenging concepts in more details than those theories which the students have already mastered. Initially, the students were encouraged to work individually to formulate diagnosis. This was followed by learning in teams and in collaboration with each other. Hence, the educationally purposeful interactive classroom activities, during the face-to-face session, enhanced students' problemsolving skills and team-based learning.

The learning of both groups was assessed at the end of clerkship through radiology case scenarios. These were aligned with the learning objectives of the course and evaluation was based on the knowledge and application skills of the students.

SPSS version 20.0 was used to compile and analyse the data. The variables included gender, end of clerkship test scores of each student, and the mean score with standard deviation of two groups. The mean of the test scores were analysed for the study using independent sample t-test, to determine if the difference in test score of two groups is statistically significant, i.e. p-value of $<0.05$.

Table II (a): Survey: Open-ended questions and responses of group B. In your opinion what are the strengths of this model.

- The interactive session after watching the videos.

- Real time learning.

- Simplicity, concepts easier to understand.

- Availability of the material even after session.

- Group discussion and brain storming.

-We can stop and replay videos when needed.

- Concepts were explained thoroughly.

- Having an introduction to the topic beforehand allows concepts to be reinforced.

- Flip class is interesting in the sense that you have an idea of what you're going to be studying. Whatever questions that you would have regarding the topic can be asked in the interactive session.

Table II (b): Survey: Open-ended questions and responses of group B, continued.

In your opinion what are the weaknesses of this model?

- Should take place in the start of rotation.

- Videos should be concise.

- Too many videos.

- The consecutive videos got monotonous".

- Lengthy.

- The absence of facilitator when watching the videos".

- A few students don't end up watching the videos/ reading the lesson because of time constraints and technical issues in opening the links. One way of solving this would be to have an extra slot of session before the class where the students are just supposed to sit together and watch the videos/read on the session".

- Another could be mandatory grading/short marked quiz at the start of the flip class.

Table I: Survey questions and frequency of responses of group B $(n=20)$.

\begin{tabular}{|c|c|c|c|c|c|}
\hline Survey questions & $\begin{array}{c}\text { 1. Strongly } \\
\text { disagree }\end{array}$ & 2. Disagree & 3. Undecided & 4. Agree & \begin{tabular}{|l} 
5. Strongly \\
agree
\end{tabular} \\
\hline Flipped class model helped you develop problem solving skills for CXR interpretation. & $0 \%$ & $0 \%$ & $5(25 \%)$ & $13(65 \%)$ & $2(10 \%)$ \\
\hline Was the class setup helpful in learning? i.e. watching videos followed by interactive session. & $0 \%$ & $1(5 \%)$ & $2(10 \%)$ & $14(70 \%)$ & $3(15 \%)$ \\
\hline The learning experience was better with the flipped classroom than with the traditional lectures/tutorials. & $0 \%$ & $3(15 \%)$ & $4(20 \%)$ & $10(50 \%)$ & $3(15 \%)$ \\
\hline
\end{tabular}


At the end of the clerkship, the students in group B completed the survey to share their experience and perception of flipped classroom model. A simplified survey was developed for this study after referral to the available literature (Table I).9,13 The survey consisted of three main items answered using a 5-point Likert scale ranging from 1 (strongly disagree) to 5 (strongly agree). At the end of the survey, there were two open-ended questions, which provided them an opportunity to share their feedback on the organisations, activities, strengths and weaknesses of the flip class model.

\section{RESULTS}

During the two rotation blocks, a total of 40 undergraduate third-year students completed their clerkship in the Radiology Department. There were 20 students in each group, i.e. in the traditional teaching and the flipped class model. There were $12(60 \%)$ girls and $8(40 \%)$ boys in group A, and 11 (55\%) girls and 9 (45\%) boys in group $B$. The mean test score of group $A$ was $7.3 \pm 1.01$ (5.5 - 9.2) and of group B was $7.2 \pm 1.12(4.8-8.8)$. Independent sample t-test showed p-value of 0.672 , which is not significant. Survey questions and responses are given in Tables I, II (a) and II (b).

\section{DISCUSSION}

Medical school education has been restructured and focusing to enhance student centred approach. The flip class strategy combines e-learning and face-to-face sessions and allows an adoptive and shared educational experience for students. ${ }^{14}$ This study was conducted in an attempt to deliver basic concept of chest X-ray, i.e. interpretation of basic imaging features through an interactive and collaborative process. This new educational pedagogy provided a clear understanding of blended learning and was implemented to inculcate critical thinking and high order learning . The redesigned course was wisely executed to determine its impact on student's educational experience. ${ }^{15,16}$

The evaluation of students' performance based on the end of clerkship test scores of the two groups (Table I) was not statistically significant. This might be related to the fact that flip class was introduced for the first time as an instructional methodology in this Department and the students compliance and understanding for the new concept was not mature enough to produce statistically significant results, as reported by other studies. ${ }^{17}$ The survey (Tables I and II), however, revealed students perception of the overall improvement in their performance through concept clarification and reinforcement of theoretical knowledge. The students were at ease during the interactive session in the flipped class format as was evident from the survey. A similar observation of students, being more comfortable and interactive with their facilitators and peers in the flipped class model, was reported by Park et al. 5
Improved performance of students in the radiology clerkships has been reported with blended learning. The students in our study also enjoyed the components of flipped class, i.e. the online modules and interactive sessions. They commented that their educational experience was positive and their learning was reinforced in the face-to-face class activity.

The students' suggestions for improvement of the flip class included dedicated time allocation to watch the tutorials during their clerkship, mandatory grading at the start of flip class to reinforce completion of assignment, i.e. watching online tutorials etc. The students also commented that the videos were lengthy and too many. In response to this, the authors like to clarify that the videos were selected by the investigators and discussed in length with the faculty who are experienced and qualified in medical education and were approved after much deliberation on content coverage.

The limitations of this study were that it was a single institution's experience and the sample size comprised of only two groups with 20 students in each group. Hence, the execution and outcome at other institutions and with larger sample size may come out to be different. The same topic was covered by the two groups each with different instructional methodology and students had more time with the flip class method then with traditional lecture-based teaching. The percent improvement with each method could not be determined as for this study a pre-post-test design was not adopted.

\section{CONCLUSION}

This study shows that the flipped classroom model had no significant impact on end-of-clerkship test scores of medical students; however, an increased perceived value and acceptability of this model was noted among the participants.

\section{ETHICAL APPROVAL:}

Approval from the Department Elective and Undergraduate Committee (EUC) and institutional Ethics Review Committee (ERC) was obtained.

\section{COFLICT OF INTEREST:}

Authors declared no conflict of interest.

\section{AUTHORS' CONTRIBUTION:}

SA: Conceived the presented study, its methodology, data collection and analysis and contributed to manuscript writing.

IM: Supervised the study, contributed to the methodology and final version of the manuscript.

\section{REFERENCES}

1. Ashley EA. Medical education - beyond tomorrow? Med Educ 2000; 34:455-9. 
2. Zafar A. Flipped class-making that one hour effective in a resource constrained setting. J Coll Physicians Surg Pak 2016; 26:795-7.

3. Irby DM, Cooke M, O'brien BC. Calls for reform of medical education by the Carnegie Foundation for the advancement of teaching: 1910 and 2010. Acad Med 2010; 85:220-7.

4. Frenk J, Chen L, Bhutta ZA, Cohen J, Crisp N, Evans T, et al. Health professionals for a new century: Transforming education to strengthen health systems in an interdependent world. Lancet 2010; 376:1923-58.

5. Park SE, Howell TH. Implementation of a flipped classroom educational model in a predoctoral dental course. J Dent Educ 2015; 79:563-70

6. Lage MJ, Platt GJ, Treglia M. Inverting the classroom: A gateway to creating an inclusive learning environment. J Econ Educ 2000; 31:30-43.

7. Illeris K. Towards a contemporary and comprehensive theory of learning. Int J Life Educ 2003; 22:396-406.

8. Pienta NJ. A "flipped classroom" reality check. J Chem Educ 2016, 93:1-2.

9. Sharma N, Lau CS, Doherty I, Harbutt D. How we flipped the medical classroom. Med Teach 2015; 37:327-30.

10. O'Connor EE, Fried J, McNulty N, Shah P, Hogg JP, Lewis P, et al. Flipping radiology education right side up. Acad Radiol 2016; 23:810-22.
11. Moffett J, Mill AC. Evaluation of the flipped classroom approach in a veterinary professional skills course. Adv Med Educ Pract 2014; 5:415-25.

12. Freeman S, Eddy SL, McDonough M, Smith MK, Okoroafor N, Jordt $\mathrm{H}$, et al. Active learning increases student performance in science, engineering, and mathematics. Proc Natl Acad Sci USA 2014; 111:8410-5.

13. Young TP, Bailey CJ, Guptill M, Thorp AW, Thomas TL. The flipped classroom: A modality for mixed asynchronous and synchronous learning in a residency program. West J Emerg Med 2014; 15:938-44.

14. Mehta NB, Hull AL, Young JB, Stoller JK. Just imagine: New paradigms for medical education. Acad Med 2013; 88:1418-23.

15. Garrison DR, Vaughan ND. Blended learning in higher education: Framework, principles, and guidelines. John Wiley \& Sons; 2008.

16. McDonald PL. Adult learners and blended learning: A phenomenographic study of variation in adult learners' experiences of blended learning in higher education. The George Washington University; 2012.

17. Belfi LM, Bartolotta RJ, Giambrone AE, Davi C, Min RJ. "Flipping" the introductory clerkship in radiology: Impact on medical student performance and perceptions. Acad Radiol 2015; 22:794-801. 